

\title{
Virtual Outcrops in a Pocket: The Smartphone as a Fully Equipped Photogrammetric Data Acquisition Tool
}

\author{
Amerigo Corradetti*, Dept. of Mathematics and Geosciences, University of Trieste, Trieste, Italy; Thomas D. Seers, Dept. of Petroleum \\ Engineering, Texas A\&M University at Qatar, Doha, Qatar; Andrea Billi, Consiglio Nazionale delle Ricerche, IGAG, Rome, Italy; and \\ Stefano Tavani, Consiglio Nazionale delle Ricerche, IGAG, Rome, Italy, and DiSTAR, Università di Napoli Federico II, Napoli, Italy
}

\begin{abstract}
Since the advent of affordable consumergrade cameras over a century ago, photographic images have been the standard medium for capturing and visualizing outcrop-scale geological features. Despite the ubiquity of raster image data capture in routine fieldwork, the development of closerange $3 \mathrm{D}$ remote-sensing techniques has led to a paradigm shift in the representation and analysis of rock exposures from two- to three-dimensional forms. The use of geological 3D surface reconstructions in routine fieldwork has, however, been limited by the portability, associated learning curve, and/ or expense of tools required for data capture, visualization, and analysis. Smartphones are rapidly becoming a viable alternative to conventional 3D close-range remote-sensing data capture and visualization platforms, providing a catalyst for the general uptake of 3D outcrop technologies by the geological community, which were up until relatively recently the purview of a relatively small number of geospatial specialists. Indeed, the continuous improvement of smartphone cameras, coupled with their integration with global navigation satellite system (GNSS) and inertial sensors provides 3D reconstructions with comparable accuracy to surveygrade systems. These developments have already led many field geologists to replace reflex cameras, as well as dedicated handheld GNSS receivers and compass clinometers, with smartphones, which offer the equivalent functionality within a single compact platform. Here we demonstrate that through the use of a smartphone and a portable gimbal stabilizer, we can readily generate and register high-quality 3D scans of outcropping geological structures, with the workflow exemplified using a mirror of a
\end{abstract}

seismically active fault. The scan is conducted with minimal effort over the course of a few minutes with limited equipment, thus being representative of a routine situation for a field geologist.

\section{INTRODUCTION AND BACKGROUND}

Rapid improvements in the fidelity of consumer-grade cameras, coupled with novel computer vision-based photogrammetric image processing pipelines (i.e., structure from motion-multiview stereo photogrammetry: SfM-MVS), have revolutionized outcrop studies over the past decade, bringing traditional field geology into the digital age. These developments are also closely tied to major methodological improvements for virtual outcrop model (VOM) interpretation. All these advancements have accelerated the use of digital outcrop data capture and analysis in field geology, transforming what was principally a visualization medium into fully interrogatable quantitative geo-data objects (Jones et al., 2004; Bemis et al., 2014; Howell et al., 2014; Hodgetts et al., 2015; Biber et al., 2018; Bruna et al., 2019; Caravaca et al., 2019; Thiele et al., 2019; Triantafyllou et al., 2019). Initially, close-range remote-sensing studies seeking to reconstruct and analyze rock outcrops were dominantly built around terrestrial laser scanning systems (terrestrial lidar), which became commercially available around two decades ago (e.g., Bellian et al., 2002). These initial works tended to be technology demonstrations rather than routine field studies, with the expense, weight, and challenging operational learning curve limiting replication to a few highly specialized geospatial specialists and groups. Receiving greater interest from the archaeological community, the adoption of digital photo- grammetry by outcrop geologists was initially slow (e.g., Hodgetts et al., 2004; Pringle et al., 2004), with legacy photogrammetric reconstruction techniques requiring highly specialized, expensive metric cameras or software (Chandler and Fryer, 2005), and commonly carried the limitation of cumbersome manual assignment of key points on the targeted rock surface (e.g., Simpson et al., 2004). Many of these disadvantages were addressed with the advent of low-cost or open-source SfM-MVS photogrammetry image processing pipelines (e.g., Snavely et al., 2006; Furukawa and Ponce, 2009; Wu, 2011), which facilitated the use of uncalibrated consumer-grade cameras and enabled automated image key-point detection and matching (e.g., James and Robson, 2012). The potential of producing 3D rock-surface models using consumer-grade cameras attracted the interest of numerous workers. These developments coupled with the increasing availability of lightweight and low-cost drones able to carry cameras and other sensors, have finally boosted the use of SfMMVS reconstruction in geosciences.

For many geoscience applications, it is necessary to register 3D rock-surface reconstructions within a local or global coordinate frame. The use of survey-grade total stations and/or real-time kinematic (RTK) differential global navigation satellite system (GNSS) antennas permit both terrestrial (Jaud et al., 2020) and aerial (Rieke et al., 2012) image data and/or ground control points (GCPs) to be georeferenced within the mapped scene with centimeter to millimeter accuracy (Bemis et al., 2014). Those survey tools are, however, bulky and expensive, and are not standard tools for geoscientists engaged in fieldwork. Improvements in consumer-grade GNSS receivers, capable of harnessing

GSA Today, v. 31, https://doi.org/10.1130/GSATG506A.1. CC-BY-NC.

*amerigo.corradetti@units.it 
multiple constellations (i.e., GPS, Glonass, Galileo, and BeiDou), now permit model geo-registration with greater simplicity and accuracies that are acceptable for many geoscientific applications. Most current smartphones are equipped with such GNSS chipsets, which enable the positioning of photos and GCPs with meter-level accuracy, or even spatial-decimeter accuracy for dual-frequency chipsets, with $>20$ min acquisition times for individual locations (Dabove et al., 2020; Uradziński and Bakuła, 2020). Under these conditions, the use of smartphones permits georeferencing of $>\sim 100$-m-wide photogrammetric models generated via terrestrial imagery (Fig. 1). The availability of photo orientation information, provided by the smartphone's inertial measurement unit (especially the magnetometer and gyroscope/accelerometer sensors), in conjunction with the GNSS position, can further improve the quality of the model registration procedure. Indeed, the photo orientation information mitigates the positional error associated with the $\mathrm{Z}$ component, and full georeferencing of $>50-60$-m-wide exposures can be achieved with a consumer-grade dual-frequency GNSS chipset-equipped smartphone (Tavani et al., 2019, 2020).

Confident georeferencing of smaller-scale outcrops with minimal equipment, however, remains challenging, limiting the utility of photogrammetric acquisition in routine geological fieldwork. In this article, we present a workflow using a smartphone and minimal accessories to address this challenge (Fig. 1) and demonstrate the applicability of using smartphone photo and video surveys of an active fault in the Apennines (Italy). Those 3D models are georeferenced by integrating the use of Agisoft Metashape and OpenPlot software tools (Tavani et al., 2019).

\section{METHODS AND DATA}

\section{The Acquisition Site}

The survey method proposed herein was performed on an outcrop of an active normal fault located within the Apennines, central Italy. A high-resolution 3D surface reconstruction of the outcrop is already available (Corradetti et al., 2021), thus allowing us to compare our results with a ground-truth model. The area contains outcropping Mesozoic rocks affected by active normal faulting. For the aforementioned survey, we focused upon one segment striking $\mathrm{N} 135^{\circ}-160^{\circ}$ (Fig. $\left.2 \mathrm{~A}\right)$. A wide $(\sim 0.3-1 \mathrm{~m})$ portion of this fault was exposed after the
Photos XYZ and orientation Single frequency GNSS

Photos orientation + Dual frequency GNSS scale and azimuth tools + dual frequency GNSS

XYZ of GCPs or photos

Single frequency GNSS

Dual frequency GNSS

RTK or differential GNSS

Total Station

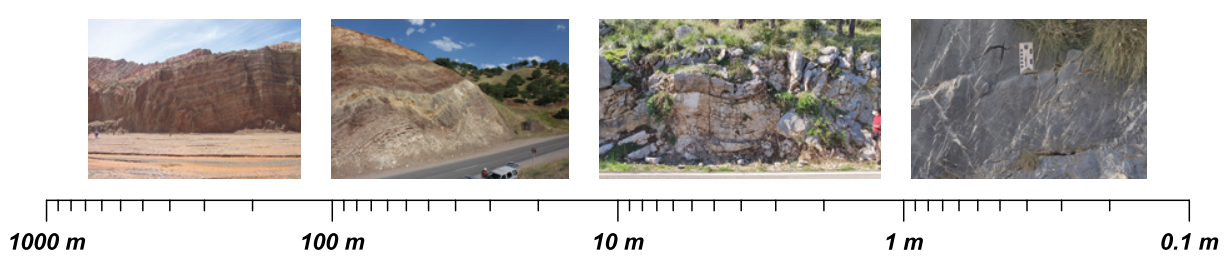

Figure 1. Scale-ranges of applicability of different methods for the registration of 3D models of outcrops, and tools used in this work. GCPs-ground control points; GNSS-global navigation satellite system; RTK-real-time kinematic.
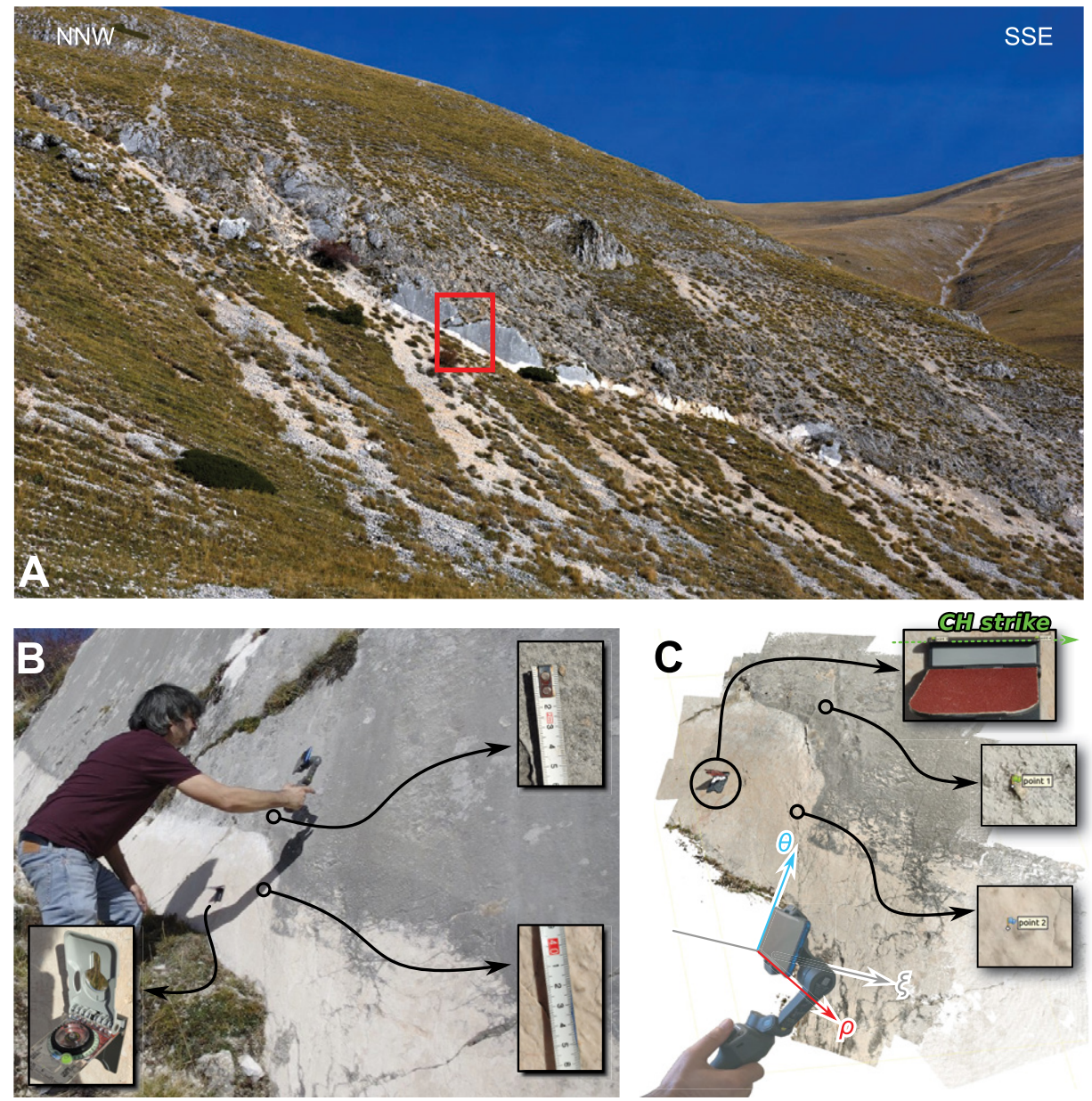

Figure 2. Photograph of the active normal fault modeled in this work (A). (B) Field set up and measurements taken before image acquisition. A ruler is used to measure the length between two points, each photographed for later recognition. A stand (compass holder, $\mathrm{CH}$ ) is placed on the outcrop and its attitude measured defining the $\mathrm{CH}$ strike. The operator can then proceed with the photo/video acquisition providing that the $\mathrm{CH}$ is left on the outcrop to be included in the model. (C) Dense point cloud of the Photo Model. In the model, four markers are added, representing the two points whose distance was measured with the tape, and two points along the $\mathrm{CH}$ strike. The $\theta, \xi$, and $\rho$ vectors of the images are also indicated. 
dramatic $M_{W} 6.5$ earthquake that struck the area on 30 Oct. 2016 (e.g., Chiaraluce et al., 2017), offering the opportunity to study this "fresh" portion of the fault surface (the white ribbon shown over the bottom of the fault surface in Fig. 2A).

\section{Pre-Acquisition Setup}

Image acquisition was carried out on 30 Oct. 2020, between 12:46 p.m. and 1:01 p.m., using a dual-frequency GNSS-equipped smartphone (Xiaomi 9T pro), hand-held gimbal, compass holder, compass-clinometer, and metric tape measure (see Fig. 1). In the field (Fig. 2B), the compass holder was placed within the scene using a detachable sticky pad with its edge approximately horizontal in relation to the Earth frame, and its trend (CH strike in Fig. 2C) measured using a Brunton TruArc 20 compass. The metric tape was used to measure the distance between two arbitrary features that later must be identified in the 3D model to provide its scaling factor. Both the compass and the metric measuring tape were removed before scene acquisition.

\section{Image Acquisition}

We produced two digital models of the fault using different approaches. The first model (from here on referred to as the Photo Model) was generated using 200 photos $(4000 \times 2250$ pixels and $4.77 \mathrm{~mm}$ focal length). The second model (from here on referred to as the Video Model) was built using 528 photos $(3840 \times 2160$ pixels and $4.77 \mathrm{~mm}$ focal length) extracted using VLC software from a 257-second-long video file (i.e., 2.6 frames per second). Both acquisitions were carried out using the smartphone mounted on a DJI OM4 gimbal, at a distance of $\sim 30 \mathrm{~cm}$ from the fault plane. To include images oblique to the fault plane, required to mitigate doming of the reconstructed scene (James and Robson, 2014; Tavani et al., 2019), the view direction was repeatedly changed within an $\sim 60^{\circ}$ wide cone. Nevertheless, avoiding operatorinduced shadows into the scene meant that the main acquisition was sub-perpendicular to the strike of the fault, being $\sim$ ENE.

\section{Image Processing and Model Registration}

Images were processed in Agisoft Metashape (version 1.6.2), resulting in two unregistered dense point clouds (Fig. 2C). Four specific markers were manually added in Metashape. In Figure 2C, Point 1 and Point
2 represent the two points whose distance was manually measured in the field. Point 3 and Point 4 were instead picked along one edge of the digitized compass holder $(\mathrm{CH}$; Fig. 2C). These are used to retrieve the trend of the $\mathrm{CH}$ strike, here coinciding with the strike of the fault plane. The rotational transformation is the most critical aspect of model registration for many geoscience applications (e.g., discontinuity, bedding plane, or geobody orientation analysis). Our survey carries different assumptions for the orientation of photographs: the short axis of the photo ( $\theta$ in Fig. $2 \mathrm{C}$ ) is pointing upward; the view direction ( $\xi$ in Fig. $2 \mathrm{C}$ ) is gently plunging and at a high angle to the fault plane; the long axis of the photo ( $\rho$ in Fig. $2 \mathrm{C}$ ) is lying horizontal, due to gimbal stabilization. The goal is to use the stabilized direction of the long axis of photos to register the vertical axis and the markers placed on the $\mathrm{CH}$ (defining the $\mathrm{CH}$ strike) to reorient the model around this vertical axis. This is done after exporting from Metashape the cameras' extrinsic parameters using the N-View Match (*.nvm) file format. The exported data include $\theta, \xi$, and $\rho$ vectors expressed in the arbitrary reference frame. Then, we exported the markers in *.txt format, which saves the estimated position of markers in the arbitrary reference frame. These files are imported in OpenPlot, where the photos' directions and the $\mathrm{CH}$ strike are computed and graphed in a stereoplot (Plot 1 in Fig. 3). For both Photo and Video models, the $\rho$ direction is clustered along a great circle, which, thanks to the gimbal, represents the horizontal plane in the real-world frame. For each model, the entire data set (i.e., the three directions of photos and the four markers) are rotated to set the $\rho$ great circle horizontal (Plot 2 in Fig. 3). Notice that the rotation axis is univocally defined, being coincident to the strike of the best-fit plane. The amount of rotation instead can be either the dip of the plane or $180^{\circ}+$ dip. The correct placement of the view direction ( $\xi$ ) means that the selection between these two options by the user is trivial. The resulting trend of the $\mathrm{CH}$ strike is $\mathrm{N} 211^{\circ}$ and $\mathrm{N} 105^{\circ}$ for the Photo and Video models, respectively. A rotation about the vertical axis $\left(57^{\circ}\right.$ counterclockwise for the Photo Model and $49^{\circ}$ clockwise for the Video Model) was applied to the entire data set to match the $\mathrm{CH}$ strike to its measured value, i.e., N154 (Plot 3 in Fig. 3). The twicerotated markers were then scaled using the measured distance between Point 1 and

\section{Photo Model Video Model}
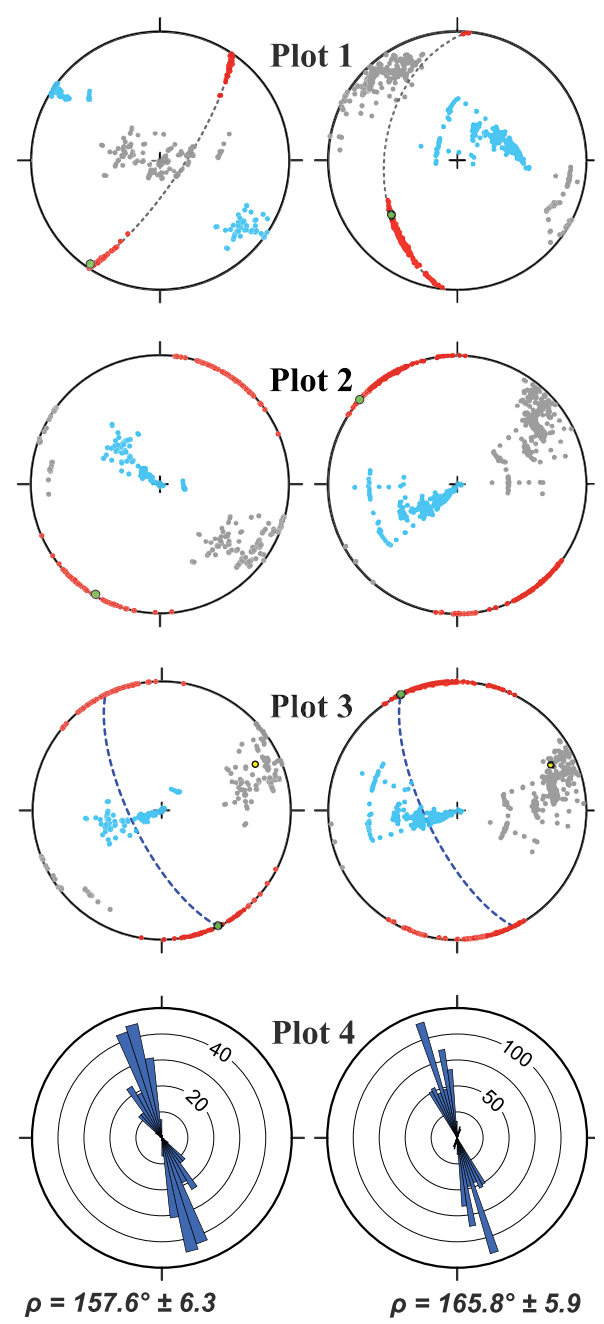

$\rho=157.6^{\circ} \pm 6.3$
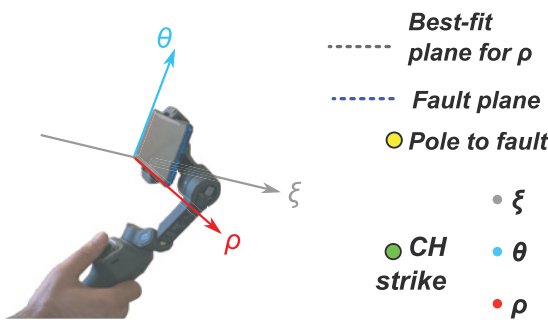

Figure 3. Lower hemisphere stereographic projection (stereonet) of the camera vectors for both the Photo and Video models, after model building (Plot 1), and after horizontalization of the $\rho$-vector great-circle envelope (Plot 2). In essence, after this rotation, the vertical axis is paralleled to the true vertical, but the azimuth is yet randomly oriented. (Plot 3) Stereonet of the camera vectors after rotation around the vertical axis. (Plot 4) Rose diagram showing the distribution of the $\rho$ vectors in both models. $\mathrm{CH}-$ compass holder.

Point 2 and were eventually fully georeferenced using the measured position of Point 1. These two steps are achieved during the export stage from OpenPlot, which compiles a *.txt file containing the correctly 
georeferenced coordinates of the four markers. This file was imported into Metashape, which allows the direct georeferencing of the model. The whole procedure, from the export or unregistered data from Metashape, through the rotations, scaling, and referencing in OpenPlot and the final re-import in Metashape takes just a few minutes and can be followed step-by-step in the supplementary video provided (see Supplementary Material $^{1}$ ). A good practice consists of checking the results and re-exporting the cameras' extrinsic data of the registered model to possibly repeat the procedure if residual rotations occur (i.e., if $\rho$ is not perfectly lying on a horizontal plane), which may relate to the proximity of the markers used for the transform and on their positional accuracy.

\section{RESULTS}

For the Photo Model, all of the 200 uploaded photos were successfully aligned and used to produce a point cloud made of $\sim 6 \times 10^{7}$ points (Fig. 4A). For the Video Model, we uploaded 735 video frames, but only 528 of them were successfully aligned and used to produce a dense cloud of $\sim 11.6 \times 10^{7}$ points (Fig. 4A). Some of the excluded images were manually removed after alignment, improving the quality of the $3 \mathrm{D}$ scene reconstruction. These images were identified through manual selection of points associated with unrealistic or blurry geometries within the sparse cloud. Often those were frames characterized by extreme overlap.

Both point clouds are characterized by zones on their boundaries, in which the 3D scene reconstruction relies on oblique images (Fig. 4B). These zones are asymmetrical, due to the aforementioned obliquity between the fault-perpendicular direction and the average photo view direction. Accordingly, we cropped the point clouds to exclude these zones and areas where the 3D reconstruction relied upon less than nine images (Fig. 4B).

The cropped point cloud for the Photo Model is composed of $\sim 2.5 \times 10^{7}$ points, whereas the cropped Video Model consists of $\sim 7.8 \times 10^{7}$ points (Fig. $4 \mathrm{C}$ ). The accuracy of these $3 \mathrm{D}$ surface reconstructions was tested by generating difference maps from the two smartphone-generated models, and between each smartphone-generated model and a high-resolution ground-truth model (from here on referred to as the Reflex
Model) built in 2016 using an image survey captured from the same outcrop with a dSLR camera (Fig. 4C). In this regard, the same fault was mapped in 2016 (Corradetti et al., 2021), using 640 images $(4272 \times 2848$ pixels) taken with a Canon EOS 450D reflex mounted on a tripod to suppress motion blur. The reconstructed area for the Reflex Model was $\sim 2.67 \mathrm{~m}^{2}$, and the point cloud included $\sim 2.7 \times 10^{8}$ points. These three point clouds were uploaded in CloudCompare (Girardeau-Montaut, 2015), where they were first manually aligned using $\sim 15$ control points for each matched point cloud, and then they were compared using the cloud-to-cloud distance tool. The resulting distance among the three clouds was generally below $4 \mathrm{~mm}$ (Fig. 4D), which decreases down to $<2 \mathrm{~mm}$ for the Photo Model versus Reflex Model.

The georeferenced Photo and Video models were then compared to evaluate differences in scaling and rotation (translation was not investigated here). To achieve this, we uploaded the two scaled and rotated models, using the compass holder as the origin of the reference frame. We aligned the two clouds using 15 control points, and the
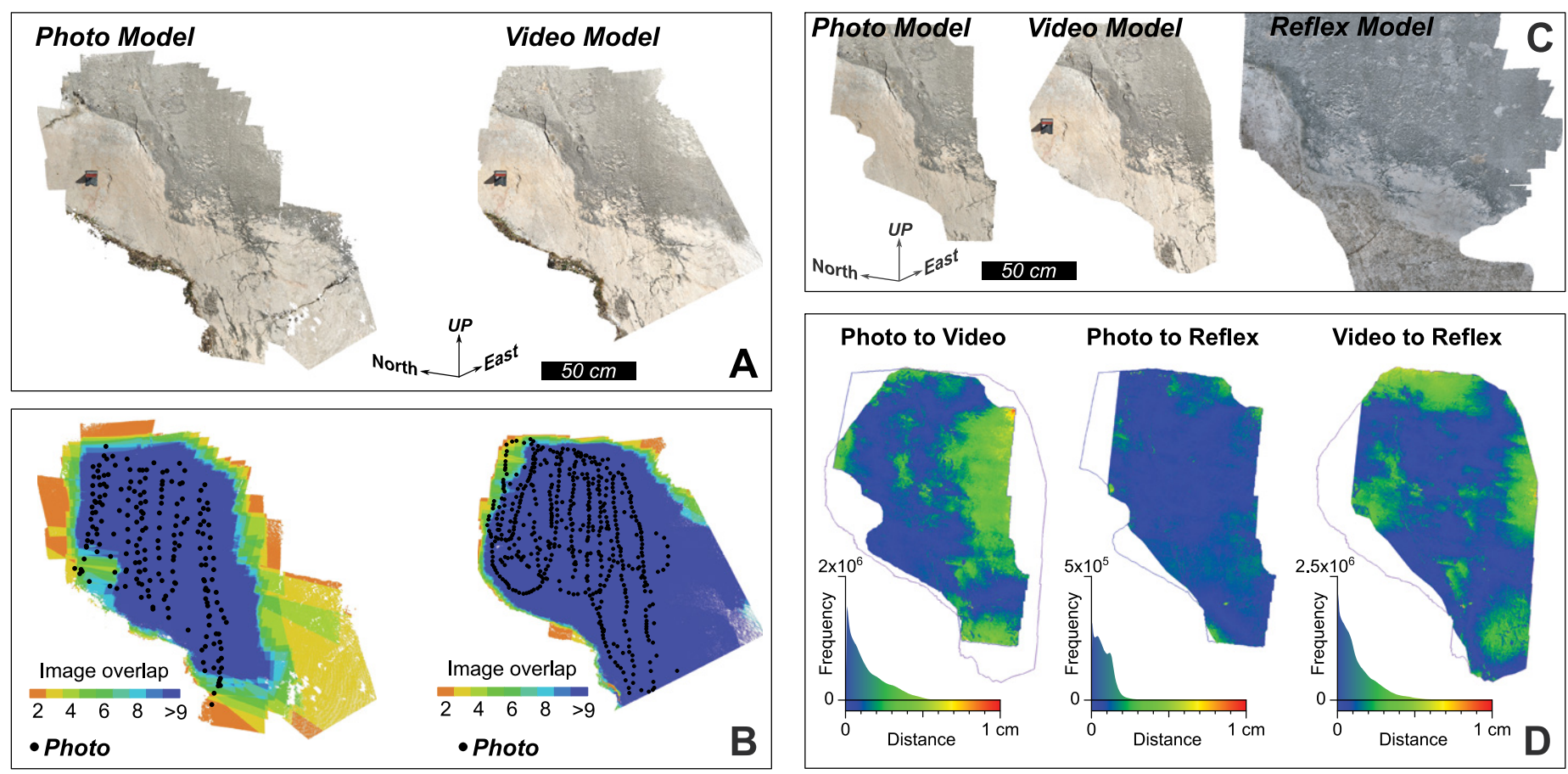

Figure 4. The Photo and Video models dense point cloud (A). (B) Images positions with respect to the models and number of images overlapping areas. (C) Cropped Photo and Video models. The Reflex Model from Corradetti et al. (2021). (D) Cloud to cloud distance between each pair of point clouds computed in CloudCompare.

\footnotetext{
${ }^{1}$ Supplemental Material. Video of the registration procedure in Metashape and OpenPlot. Metashape reports. Go to https://doi.org/10.1130/GSAT.S.14751042 to access the supplemental material; contact editing@geosociety.org with any questions.
} 
result is a transformation matrix indicating that to align the two point clouds, a scaling factor of 1.0012 is required. The rotations around the $\mathrm{X}, \mathrm{Y}$, and $\mathrm{Z}$ axes are $-0.38^{\circ}$, $1.00^{\circ}$, and $0.34^{\circ}\left(1.1^{\circ}\right.$ around the strike direction and $0.29^{\circ}$ around the horizontal direction perpendicular to the strike).

\section{DISCUSSION}

We have described a workflow for generating georeferenced 3D models of geological outcrops ranging in size from tens of meters down to a few centimeters. The required tools are extremely portable. Their use in the field is straightforward, with survey acquisition taking a few minutes for our case study. During the development and testing of the procedure, it was notable that video sequence acquisition can provide a more coherent scene, assuming that the mapped area is relatively continuous. On the other hand, video sequences may generate excessive scene overlap, complicating image matching. Also, the use of video frames implies the lack of control on shutter speed, aperture, ISO, etc., limiting the use of video frames mostly to small outcrops. Thus, selectively captured still images generally ensure a better result and a shorter processing time, as long as the acquisition is correctly carried out. Video models instead provide a simpler acquisition scheme, albeit with greater risk of reconstruction artifacts.

Once the models are built, post-processing registration using the proposed method is also straightforward for geoscientists with limited knowledge of geospatial data processing and analysis. From a practical point of view, the use of a low-cost, lightweight gimbal smartphone stabilizer offers a key improvement to similar workflows proposed previously (e.g., Tavani et al., 2020), and it is encouraged that geoscientists who want to replicate the presented acquisition strategy include this item as part of their standard equipment. Using a gimbal offers two substantial advantages. First, stabilization of the smartphone during acquisition improves image quality (i.e., by limiting motion blur), with the produced 3D model rivaling an equivalent surface reconstruction produced with a higher resolution dSLR mounted on a tripod. The second but most fundamental advantage of using a gimbal is the stabilization of the smartphone along its long axis, so that all the images produced are oriented along a horizontal plane, providing a constraint for our georeferencing procedure.
Two data sets, (i.e., photos and images extracted from a video sequence) have been tested to produce and later register the Photo and Video models, respectively. These models have been compared together and with the Reflex Model, which represents a benchmark build with photos obtained in 2016, although probably minor morphological changes due to weathering can have occurred since then. Manual alignment of the Photo and Video models shows that discrepancies ranging from 0 to $5 \mathrm{~mm}$ occur between the surface reconstructions. There are notable discrepancies between the Video and Reflex models, whereas the Photo and Reflex models are much more comparable, with surface displacements ranging between 0 and $2 \mathrm{~mm}$. Despite the lower number of input photos, the Photo Model outperforms the Video Model in terms of accuracy. The major reason for this is the problematic reconstruction of the scene from extremely narrow baseline images extracted from the video sequence. Despite the video capture having a more straightforward acquisition procedure, it may require a more complex and time-consuming userassisted procedure of image selection and repeated runs of photo alignment.

Apart from minor differences in reconstruction quality and errors that may arise from manual detection of the key points used in the similarity transform, the registration procedure of the two smartphone-generated models led to models with consistent orientation and scaling characteristics. In detail, we observed a rotation about the vertical axis of $0.34^{\circ}$. This error, which mostly relates to digitization of the reconstructed $\mathrm{CH}$ placed within the scene, is negligible for many geological applications, particularly if compared with the accuracy of analog compasses (e.g., Allmendinger et al., 2017). Such minimal value, however, does not reflect field measurement accuracy, since only one measurement was made of the same object present in the two models. Models of the same geological object, created by different individuals at different times, could introduce additional rotational errors. A slight misalignment of the registered horizon between the two models is reflected by the observed rotations around the $x$ and $y$ axes of $-0.38^{\circ}$ and $1.00^{\circ}$, respectively. This misalignment is attributable to the procedure of horizontalization of $\rho$ : as seen in the rose diagram of Figure 3, $\rho$ in both models is clustered along a direction that is nearly parallel to the strike of the fault, providing a greater constraint along the fault parallel direction than along its perpendicular. Indeed, the discrepancy in the estimated horizontal plane between the two models, considering the orientation of the fault, is $1.1^{\circ}$ around the strike direction and $0.29^{\circ}$ around the horizontal direction perpendicular to the fault's strike. In other words, the registration of the horizontal plane is sensitive to the orientation of the photographs, so that the inclusion of oblique to the scene photographs may improve the "horizontalization" of $\rho$.

\section{CONCLUSION}

This paper faces the need encountered by many field geologists to efficiently capture images of outcrops with ultra-portable tools to produce detailed, scaled, and properly oriented "pocket" 3D digital representations of rock exposures. Submillimeter point-cloud resolution is achieved with the suggested procedure, equaling that of models obtained by means of reflex cameras, and proving the efficiency of the proposed registration procedure for several quantitative applications in geology (e.g., fracture and fault orientation and associated kinematic indicators, bedding attitude and thickness, fault roughness, etc.). Furthermore, the proposed method is intuitive so that it can be applied by all geoscientists irrespective of background or experience. In this regard, we hope that this workflow will favor the widespread use of 3D models from smartphones.

\section{REFERENCES CITED}

Allmendinger, R.W., Siron, C.R., and Scott, C.P., 2017, Structural data collection with mobile devices: Accuracy, redundancy, and best practices: Journal of Structural Geology, v. 102, p. 98-112, https://doi.org/10.1016/j.jsg.2017.07.011.

Bellian, J.A., Jennette, D.C., Kerans, C., Gibeaut, J., Andrews, J., Yssldyk, B., and Larue, D., 2002, 3-dimensional digital outcrop data collection and analysis using eye-safe laser (LIDAR) technology: American Association of Petroleum Geologists Search and Discovery Article 40056, https:// www.searchanddiscovery.com/documents/beg3d/ (last accessed 27 Feb. 2021).

Bemis, S.P., Micklethwaite, S., Turner, D., James, M.R., Akciz, S., Thiele, S.T., and Bangash, H.A., 2014, Ground-based and UAV-based photogrammetry: A multi-scale, high-resolution mapping tool for structural geology and paleoseismology: Journal of Structural Geology, v. 69, p. 163-178, https://doi.org/10.1016/j.jsg.2014.10.007.

Biber, K., Khan, S.D., Seers, T.D., Sarmiento, S., and Lakshmikantha, M.R., 2018, Quantitative characterization of a naturally fractured reservoir analog using a hybrid lidar-gigapixel imaging approach: Geosphere, v. 14, p. 710-730, https://doi.org/10.1130/GES01449.1.

Bruna, P.O., Straubhaar, J., Prabhakaran, R., Bertotti, G., Bisdom, K., Mariethoz, G., and Meda, M., 2019, A new methodology to train fracture network simulation using multiple-point statistics: 
Solid Earth, v. 10, p. 537-559, https://doi.org/ 10.5194/se-10-537-2019.

Caravaca, G., Le Mouélic, S., Mangold, N., L'Haridon, J., Le Deit, L., and Massé, M., 2019, 3D digital outcrop model reconstruction of the Kimberley outcrop (Gale crater, Mars) and its integration into virtual reality for simulated geological analysis: Planetary and Space Science, v. 182, 104808, https://oi.org/10.1016/j.pss.2019.104808.

Chandler, J.H., and Fryer, J.G., 2005, Recording aboriginal rock art using cheap digital cameras and digital photogrammetry, in Proceedings of CIPA (Comité International de la Photogrammétrie Architecturale [International Committee of Architectural Photogrammetry], p. 193-198, https://www.cipaheritagedocumentation.org/ wp-content/uploads/2018/12/Chandler-FryerRecording-aboriginal-rock-art-using-cheap-digitalcameras-and-digital-photogrammetry.pdf (last accessed 6 June 2021).

Chiaraluce, L., et al., 2017, The 2016 central Italy seismic sequence: A first look at the mainshocks, aftershocks, and source models: Seismological Research Letters, v. 88, p. 757-771, https://doi .org/10.1785/0220160221.

Corradetti, A., Zambrano, M., Tavani, S., Tondi, E., and Seers, T.D., 2021, The impact of weathering upon the roughness characteristics of a splay of the active fault system responsible for the massive 2016 seismic sequence of the Central Apennines, Italy: Geological Society of America Bulletin, v. 133, p. 885-896, https://doi.org/10.1130/B35661.1.

Dabove, P., Di Pietra, V., and Piras, M., 2020, GNSS positioning using mobile devices with the android operating system: ISPRS International Journal of Geo-Information, v. 9, https://doi.org/10.3390/ ijgi9040220.

Furukawa, Y., and Ponce, J., 2009, Accurate, dense, and robust multiview stereopsis: IEEE Transactions on Pattern Analysis and Machine Intelligence, v. 32, p. 1362-1376, https://doi.org/10.1109/ TPAMI.2009.161.

Girardeau-Montaut, D., 2015, Cloud compare-3D point cloud and mesh processing software: Open Source Project, https://www.danielgm.net/cc/ (last accessed 6 June 2021).

Hodgetts, D., Drinkwater, N.J., Hodgson, J., Kavanagh, J., Flint, S.S., Keogh, K.J., and Howell, J.A., 2004, Three-dimensional geological models from outcrop data using digital data collection techniques: An example from the Tanqua Karoo depocentre, South Africa, in Curtis, A., and Wood.,
R., eds., Geological Prior Information: Informing Science and Engineering: Geological Society, London, Special Publication 239, p. 57-75, https:// doi.org/10.1144/GSL.SP.2004.239.01.05.

Hodgetts, D., Seers, T., Head, W., and Burnham, B.S., 2015, High performance visualisation of multiscale geological outcrop data in single software environment, in 77th EAGE Conference and Exhibition 2015: European Association of Geoscientists \& Engineers, p. 1-5, https://doi .org/10.3997/2214-4609.201412862.

Howell, J.A., Martinius, A.W., and Good, T.R., 2014, The application of outcrop analogues in geological modelling: A review, present status and future outlook, in Martinius, A.W., Howell, J.A., and Good, T.R., eds., Sediment-Body Geometry and Heterogeneity: Analogue Studies for Modelling the Subsurface: Geological Society, London, Special Publication 387, p. 1-25, https:// doi.org/10.1144/SP387.12.

James, M.R., and Robson, S., 2012, Straightforward reconstruction of $3 \mathrm{D}$ surfaces and topography with a camera: Accuracy and geoscience application: Journal of Geophysical Research, v. 117, F03017, https://doi.org/10.1029/2011JF002289.

James, M.R., and Robson, S., 2014, Mitigating systematic error in topographic models derived from UAV and ground-based image networks: Earth Surface Processes and Landforms, v. 39, p. 1413-1420, https://doi.org/10.1002/esp.3609.

Jaud, M., Bertin, S., Beauverger, M., Augereau, E., and Delacourt, C., 2020, RTK GNSS-assisted terrestrial SfM photogrammetry without GCP: Application to coastal morphodynamics monitoring: Remote Sensing, v. 12, p. 1889, https:// doi.org/10.3390/rs12111889.

Jones, R.R., McCaffrey, K.J.W., Wilson, R.W., and Holdsworth, R.E., 2004, Digital field data acquisition: Towards increased quantification of uncertainty during geological mapping, in Curtis, A., and Wood., R., eds., Geological Prior Information: Informing Science and Engineering: Geological Society, London, Special Publication 239, p. 4356, https://doi.org/10.1144/GSL.SP.2004.239.01.04.

Pringle, J.K., Westerman, A.R., Clark, J.D., Drinkwater, N.J., and Gardiner, A.R., 2004, 3D highresolution digital models of outcrop analogue study sites to constrain reservoir model uncertainty: An example from Alport Castles, Derbyshire, UK: Petroleum Geoscience, v. 10, p. 343352, https://doi.org/10.1144/1354-079303-617.
Rieke, M., Foerster, T., Geipel, J., and Prinz, T., 2012, High-precision positioning and real-time data processing of UAV-systems: ISPRS International Archives of the Photogrammetry: Remote Sensing and Spatial Information Sciences, v. XXXVIII-1, C22, p. 119-124, https://doi.org/10.5194/ isprsarchives-XXXVIII-1-C22-119-2011.

Simpson, A., Clogg, P., Díaz-Andreu, M., and Larkman, B., 2004, Towards three-dimensional non-invasive recording of incised rock art: Antiquity, v. 78, p. 692-698, https://doi.org/10.1017/ S0003598X00113328.

Snavely, N., Seitz, S.M., and Szeliski, R., 2006, Photo tourism: ACM Transactions on Graphics, v. 25, p. 835, https://doi.org/10.1145/1141911.1141964.

Tavani, S., Corradetti, A., Granado, P., Snidero, M., Seers, T.D., and Mazzoli, S., 2019, Smartphone: An alternative to ground control points for orienting virtual outcrop models and assessing their quality: Geosphere, v. 15 , p. 2043-2052, https://doi.org/10.1130/GES02167.1.

Tavani, S., Pignalosa, A., Corradetti, A., Mercuri, M., Smeraglia, L., Riccardi, U., Seers, T., Pavlis, T., and Billi, A., 2020, Photogrammetric 3D model via smartphone GNSS sensor: Workflow, error estimate, and best practices: Remote Sensing, v. 12, 3616, https://doi.org/10.3390/rs12213616.

Thiele, S.T., Grose, L., Cui, T., and Cruden, A.R., 2019, Extraction of high-resolution structural orientations from digital data: A Bayesian approach: Journal of Structural Geology, https:// doi.org/10.1016/j.jsg.2019.03.001.

Triantafyllou, A., Watlet, A., Le Mouélic, S., Camelbeeck, T., Civet, F., Kaufmann, O., Quinif, Y., and Vandycke, S., 2019, 3-D digital outcrop model for analysis of brittle deformation and lithological mapping (Lorette cave, Belgium): Journal of Structural Geology, v. 120, p. 55-66, https://doi.org/10.1016/j.jsg.2019.01.001.

Uradziński, M., and Bakuła, M., 2020, Assessment of static positioning accuracy using low-cost smartphone GPS devices for geodetic survey points' determination and monitoring: Applied Sciences (Switzerland), v. 10, p. 1-22, https://doi .org/10.3390/app10155308.

Wu, C., 2011, VisualSFM: A visual structure from motion system: http://ccwu.me/vsfm/ (last accessed 6 June 2021).

Manuscript ReCeived 5 Mar. 2021

REVISED MANUSCRIPT RECEIVED 19 MAY 2021

MANUSCRIPT ACCEPTED 25 MAY 2021 